\author{
Boris Nudelman \\ Engineering Services \\ E-mail: nudelman.boris@gmail.com
}

\title{
ALUMINUM PROFILES EXTRUSION PROCESS ANALYSIS. MECHANICAL ASPECTS
}

\author{
Борис Нудельман \\ Engineering Services \\ E-mail: nudelman.boris@gmail.com \\ НЕКОТОРЫЕ АСПЕКТЫ МЕХАНИКИ ПРОЦЕССА ЭКСТРУЗИИ \\ АЛЮМИНИЕВЫХ ПРОФИЛЕЙ
}

The presented paper subject is the engineering analysis of the aluminum profiles hot extrusion. Some theoretical aspects of the process as described in professional publications have unsufficient physical grounds. The imperfections of the theory supply a platform for arbitrary interpretations and distorted understanding of the process. Particularly, this relates to the billet friction problem. The paper is addressed primarily to practical engineers with the aim to give them physically consistent process imagine. Some principal solutions to the process were developed in the paper: billet friction by liner; the plastic flow model in dummy block region; the stress state and flow beginning relations in the die opening zone. General model of stable metal flow relations in the billet volume was formulated. The analysis of all mentioned above problems fulfilled by the uniform methodology with the necessity simplifications. The uniform field stress state was used as base model. Strain energy minimum principal for static relations and mass transfer energy minimum principal for plastic flow relations were used generally. Numerical estimations of given solutions were fulfilled. Principal stress component ratio in uniform stress of three dimensional compressing field was defined. Billet - liner, billet - dummy block friction forces acting model was developed. By appraisal, billet - liner friction force does not exceed about $31 \%$ of summative press force. The region of friction force acting was defined. The region restricted as rather short distance from dummy block. Surface forces accumulation effect was revealed. Probable model of plastic flow in dummy block region is presented. Investigation of stress state in die opening region was fulfilled. Additional stresses field in the region revealed. Configuration of the field was defined with numerical estimation. The field in great degree defines the necessary stress level for metal flow start and stable process. The algorithm of maximal flow stress definition was developed. The flow model with restricted shear strain was presented. Preferable flow direction is radial, relative to die opening. Essential interdependencies and general relations of billet metal flow are presented. The analyses of press load by dummy block displacement graph was fulfilled. No contradictions with the theoretically achieved results were revealed. The results experimental confirmation and further introduction to practice are proposed.

Key words: extrusion, dummy block, billet, stress, force, friction, plastic flow, die, equation, solution.

Содержанием представленной работы является инженерный анализ процесса горячей экструзии алюминиевых профилей. Некоторые аспекты этого процесса освещены в специальной литературе без достаточных физических оснований. Недостатки теории создают возможность произвольных толкований и искажен-ных представлений о процессе. В частности, это относится к проблеме трения заготовки. Работа адресована, инженерам практикам с целью дать физически непротиворечивое теоретическое представление о процессе. На теоретическом уровне рассмотрены вопросы трения заготовки. Представлена возможная модель пластического течения в зонах пресс блока и формирующего отверстия матрицы. Сформулированы условия для общей модели стабильного пластического течения металла в объёме. Анализ всех задач выполнен по единой методике. В качестве базовой использована модель напряженного состояния в однородном поле. Как дополнительные условия использованы принцип минимума энергии деформации для статической системы, минимума энергии массопереноса для условий пластического течения. Произведены численные оценки полученных решений. Разработана базовая схема напряженного состояния при объемном сжатии материала с активной линейной нагрузкой. Определены соотношения главных компонент напряжений в однородном поле. Определена модель действия сил трения заготовки по поверхности гильзы контейнера и пресс блока. Выявлен эффект накопления поверхностных сил. Оценен уровень влияния трения на процесс экструзии. По оценке сумма сил трения не превышает $31 \%$ от усилия пресса. Определена область действия сил трения. Область ограничена только зоной, близкой к пресс блоку. Разработана вероятная модель течения материала в зоне контакта пресс блока с гильзой контейнера. Выполнено исследование напряженного состояния в зоне формирующего отверстия матрицы. Выявлено наличие поля дополнительных напряжений. Произведена количественная оценка его конфигурации. Поле в большой степени определяет необходимый уровень напряжений начала и стабильного процесса течения металла. Представлена модель течения с ограничением сдвиговых деформаций на примере круглого отверстия в матрице. Преимущественным направлением течения является радиальное по отношению к отверстию в матрице. Предложены исходные соотношения и общие условия течения металла в объеме заготовки. Произведен анализ интегрального графика нагрузки пресса по ходу пресс-блока. Не выявлено расхождений с полученными в анализе теоретическими выводами. Предложены направления для их экспериментального подтверждения и практического использования.

Ключевые слова: экструзия, пресс-блок, заготовка, напряжение, сила, трение, пластическое течение, матрица, уравнение, решение. 


\section{Introduction}

The presented analysis subjects are several aspects of the aluminum profiles hot extrusion process. In order to avoid ambiguity, the process of direct extrusion fulfills in a hydraulic press with the following scheme and cycle elements.

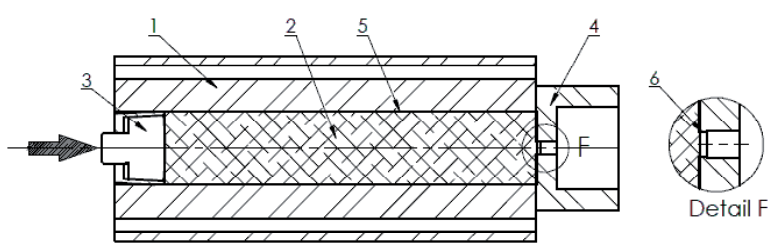

Figure 1.1 - The process scheme: 1 - container,

2 - billet, 3 -dummy block, 4 -die, 5 - liner and billet contact surface, 6 - die bearing

The state and position of the elements are as follows: the container is pressed to die with sealing force; billet in the liner hollow after burp cycles, whole volume is filled with billet material; the pressure is being raised by the slow motion of the dummy block (work stroke beginning ).

The former reason for present analysis was necessity to find the rationale for some extrusion technology improvements. As the work went on, theoretical contradictions (on the author's opinion) in some principal positions were revealed. Particularly, the friction influence on the extrusion process as presented in the theoretical model of friction in monograph [1], to which the most of other authors refer [2], [3], [4]. On the other hand, the point of view of a number of operative specialists do not match the theoretical predictions of results. Hence, because of impossibility to use even partly the existed calculation methods, the author was necessitated to start the analysis from the base positions. It was a good piece of job made before this decision. In the beginning the author's view of the problem did not differ from the traditional ones. The first probe of analysis targeting polycrystalline fibers extrusion was fulfilled with the traditional process model. No productive results were achieved, no way to improve the process was found, no cause of worse changes of fibers microstructure was revealed. The author also has to note, that the present analysis results are based on a huge experience achieved by specialists of the aluminum industry branch. Especially it relates to experimental elaborations. Two works [5] and [6] were more helpful to find out the way of solving the friction problem with the minimum level of abstraction.

\section{Friction along inside liner surface}

2.1 Billet volume stress state

Again we repeat the initial state. The whole container volume is filled with the billet material. The inner pressure is being raised by dummy block action till the value of $\sigma_{z} \leq \sigma_{e}$ - the plastic flow beginning ( Fig. 2.1 ).

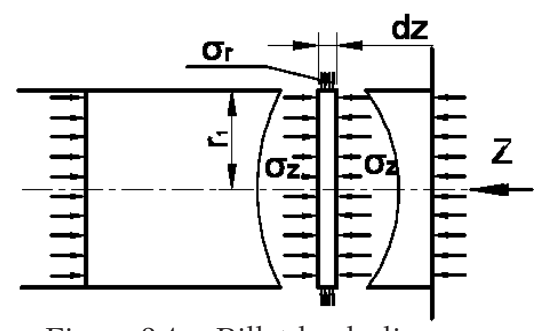

Figure 2.1 - Billet loads diagram

The stress state of the disc with the width $\mathrm{d}_{z}$ on any distance from the die surface is considered. Without significant strains the flat sections hypothesis considered rightful. The axis directed stresses uniformly distributed on the side disc surface. Friction stresses on the outer cylindrical surface are absent or negligible without any displacement. An element of the disc volume at any point of side surface is considered (Fig. 2.2).

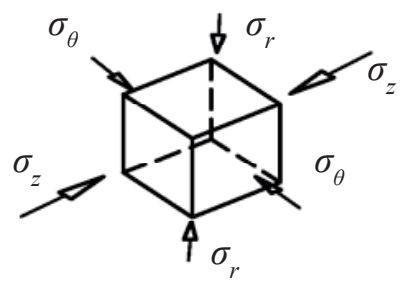

Figure 2.2 - Volume element. Stress components before plastic flow

The element faces are in the same as principal stresses directions: $\sigma_{z,} \sigma_{r} \sigma_{\theta}$, where $\sigma_{z}-$ axis direction stress; $\sigma_{r}$ - radial stress; $\sigma_{\theta}$ - considered as tangential stress. Because $\sigma_{z}$ is the active one and by axisymmetric relation the principal compressive stress $\sigma_{z}=\sigma_{3}$, therefore $\sigma_{\mathrm{r}}$ and $\sigma_{\theta}$ are principal stress components also. It seems illegitimately to use Generalized law of elasticity in presented three dimensional compressive stress state without any verification: 
In the principal stress symbols:

$$
\begin{aligned}
& \varepsilon_{1}=\frac{1}{E}\left(\sigma_{1}-\mu \sigma_{2}-\mu \sigma_{3}\right) \\
& \varepsilon_{2}=\frac{1}{E}\left(\sigma_{2}-\mu \sigma_{1}-\mu \sigma_{3}\right) \\
& \varepsilon_{3}=\frac{1}{E}\left(\sigma_{3}-\mu \sigma_{1}-\mu \sigma_{2}\right)
\end{aligned}
$$

In presented components:

$$
\begin{gathered}
\varepsilon_{z}=\frac{1}{E}\left(\sigma_{z}-\mu \sigma_{r}-\mu \sigma_{\theta}\right) \\
\varepsilon_{r}=\frac{1}{E}\left(\sigma_{r}-\mu \sigma_{z}-\mu \sigma_{\theta}\right) \\
\varepsilon_{Q}=\frac{1}{E}\left(\sigma_{\theta}-\mu \sigma_{z}-\mu \sigma_{r}\right)
\end{gathered}
$$

Interdependences (2.1) allow random component values. Strain formulas do not match the compatibility relations: the strain component caused by $\sigma_{\mathrm{z}}=\sigma_{3}$ in $\sigma_{2}$ and $\sigma_{1}$ directions required either opposite sign strain of adjacent elements or their displacement. Both are impossible in three dimentional compressive state. Adjacent disc volume elements are under the same conditions. In other words we may consider that stress field of either differential part of volume is uniform. Furthermore, the liner inside surface remains fixed. (Actually radial liner strain does exist, but it is negligible, because the liner - container fit stiffness about 10 times exeeds the heated billet's one.) Thus, it is rightful to consider radial displacement absent $-u_{r}=0$; and tangential $-u_{\theta}=0-$ as well, because of axisymmetric relation. So, the only possible stress state remaining the uniform field:

$$
\begin{gathered}
\varepsilon_{z}=f\left(\sigma_{z}\right) ; \\
\varepsilon_{r}=\varepsilon_{\theta}=0 ; \\
\sigma_{r}=\sigma_{\theta}=f\left(\sigma_{z}\right)
\end{gathered}
$$

We have no experimental data of interdependences in three dimensional compressive state. Hence, we need to use the superposition principal to define them, whenever possible without physical relations distortion. So, we have the elastic law for linear stress state, rightful up to known stress level:

$$
\begin{gathered}
\sigma_{z}=E \varepsilon_{z} \\
\varepsilon_{\theta}^{\prime}=\varepsilon_{r}^{\prime}=-\mu \varepsilon_{z},
\end{gathered}
$$

where $E$ and $\mu$ - are constants or functions of stress-strain dependence in the acting stress range; $\varepsilon_{\theta}^{\prime}=\varepsilon_{r-\text { virtual feasible strain components in } \mathrm{r}}^{\prime}$ and $\theta$ directions of $\sigma_{z}$ action. Whereas. $\varepsilon_{z}$ is negative in compressive state, than $\varepsilon_{\theta}^{\prime}=\varepsilon_{r}^{\prime}>0$. Full virtual strain $\varepsilon_{\theta}$ consists of the three components:

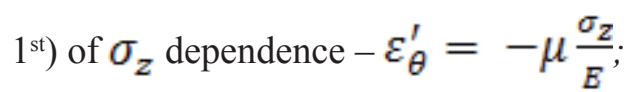

$2^{\text {nd }}$ ) of $\sigma_{\theta}$ dependence $-\varepsilon_{\theta}^{\prime \prime}=\frac{\sigma_{\theta}}{E}$;

$\left.3^{\mathrm{d}}\right)$ of $\sigma_{r}$ dependence $-\varepsilon_{\theta}^{\prime \prime \prime}=-\mu \frac{\sigma_{r}}{E}$.

Equation for $\sigma_{\theta}$ definition with (2.2):

$$
\varepsilon_{\theta}=\frac{\sigma_{\theta}}{E}-\mu \frac{\sigma_{z}}{E}-\mu \frac{\sigma_{r}}{E}=0,
$$

From which:

$$
\sigma_{\theta}=\sigma_{r}=\frac{\mu}{1-\mu} \sigma_{z}
$$

Resulting real linear strain in three dimensional stress state with resistance:

$\varepsilon_{z}=\frac{\sigma_{z}}{E}-\mu\left(\frac{\sigma_{\theta}}{E}+\frac{\sigma_{r}}{E}\right)=\frac{\left(1-2 \frac{\mu^{2}}{1-\mu}\right) \sigma_{z}}{E}$

The (2.5) is the base formula of present analysis. It defines compressive stress components ratio in principal directions in differential part of stress field. Note, that (2.5) may be received directly from (2.1) system with formulated above relations. The (2.5) ratio still remains a hypothesis and is necessary to be explained, that all other ratios are impossible with the defined restrictions. For example,

$$
\sigma_{2} \neq \sigma_{1},\left|\sigma_{1}\right|<\left|\frac{\mu}{1-\mu} \sigma_{3}\right|,
$$

where $\sigma_{3}$ is greatest by absolute value negative active stress. This virtual state means that in both sides of $\sigma_{1}$ direction (at two faces) the element is unbalanced and the strain will continue till balance. Second example, $\sigma_{2} \neq \sigma_{1}$, and 


$$
\left|\sigma_{2}\right|>\left|\frac{\mu}{1-\mu} \sigma_{3}\right|
$$

$\sigma_{3}$ was defined as greatest active compressive stress, ergo principal stress. Exceeding of (2.7) in one of both remaining directions means, that there is an active stress source in this direction. It causes that $\sigma_{3}$ and its direction is not principal. The principal direction and value

will be: $\overrightarrow{\sigma_{g}}=\overrightarrow{\sigma_{3}}+\overrightarrow{\left[\sigma_{2}-\left(\frac{\mu}{1-\mu} \sigma_{3}\right)\right]}$, and $\sigma_{g}=-\sqrt{\sigma_{3}^{2}+\sigma_{2}^{2}}$.

Reactions in both remaining directions will equalize to (2.5) ratio if plastic flow does not occur. The (2.5) parameters: E - Strain Resistance Modulus and $\mu$-stress components ratio fully define the material behavior. Their dependence on the stress level should be defined experimentally.

\subsection{The friction forces model}

The integral load circuit applied on the billet includes (Fig. 2.1):

1) distributed on whole surface active dummy block load in axis direction;

2) distributed on whole surface active die reaction load in inverse direction;

3) liner radial reaction along whole cylindrical outer surface;

4) acting in axis direction friction forces, caused by radial liner pressure and axial material displacement ( not shown in fig. 2.1).

Analysis initial relations: whole liner volume filled with billet material; the billet loaded till plastic flow stress $\sigma_{z}=\sigma_{e}$, which acts to some distance z from die surface. Since there is no peripheral material displacement, the friction forces are absent too. Consider equilibrium of differential disc of width $d z_{1}$ of billet (Fig. $2.3 \mathrm{a}$ ) on a distance from die surface. Assuming that disc zero position by $z_{1}$ is on the border of material axial displacement start. Ergo at that point the friction forces appear.

The next step of present analysis would be the definition of the influence of friction by liner surface on the billet. Wherein the usual approach, that considers the yielding pressure acting without any change in radial direction, seems illogical.

From (2.5) the radial pressure:

$$
\sigma_{r}(0)=\frac{\mu}{1-\mu} \sigma_{z 1}(0)=\frac{\mu}{1-\mu} \sigma_{e}
$$

Accepting friction law in Coulomb form - the friction force by area unit is proportional to the normal pressure (in the same manner as in [6 ]):

$$
f_{f}=k \sigma_{r},
$$

where friction factor $\mathrm{k}$ is considered as constant from known range [6]: 0.6..1.0. The 1.0 value matches sticking friction relations. The start friction force value by area unit from (2.8):

$$
f_{f}\left(z_{1}=0\right)=k \frac{\mu}{1-\mu} \sigma_{e}
$$

The elementary force in random section by $z_{1}$ from friction forces region:

$$
f_{f}\left(z_{1}\right)=k \frac{\mu}{1-\mu} \sigma_{z 1}\left(z_{1}\right)
$$

The billet reaction on friction force analysis was not found in known to author publications. Usually, most of them announce that the shear

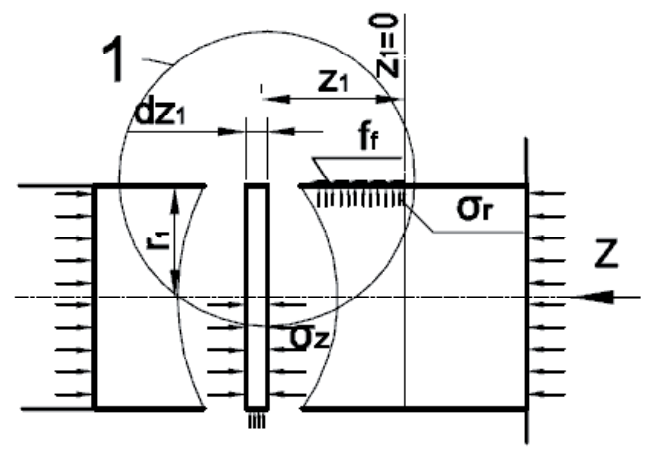

a)

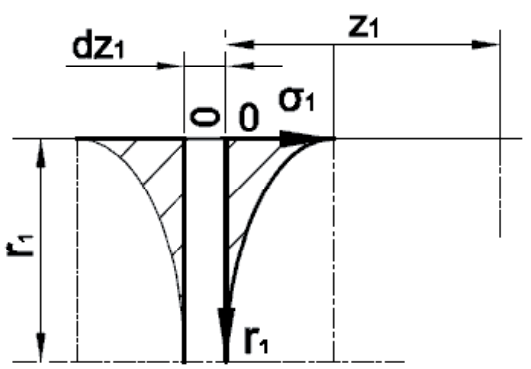

b)

Figure 2.3 - a - friction forces diagram; $\mathrm{b}$ - reaction stresses distribution in the billet volume 
stresses exceed the ultimate level, thus a shear strain appears in the layers on some distance from outer surface. This does not seem right. It would be more correct to rely on the general polycrystalline materials property, including aluminum alloys, to resist to outer loads.

The friction force, acting by the surface causes reaction in the billet each section, that equal by value and inversed by direction $-N_{\mathrm{z}}$. "Superficially" looking. lets consider for example that the reaction distributed in the layer of 10 molecules or 10 crystallites of $10 \mu \mathrm{m}$ each. It definitely contradicts with continuity and isotropy relations, because requires some "jump" of properties on the border. Moreover it contradicts with minimum strain work principal:

$$
\begin{gathered}
w=\frac{\sigma_{z 1} \varepsilon_{z 1}}{2}-\text { energy; } \\
\varepsilon_{z 1}=\frac{\sigma_{z 1}}{E}-\text { strain; } \\
\sigma_{z 1}=\frac{N_{z}}{0.01 \mathrm{~cm} 1 \mathrm{~cm}}-\text { stress. }
\end{gathered}
$$

Actually, distributed in radial direction the function $\sigma_{z 1}$ has to match following relations (Fig.2.3 b):

1) continuous;

2) limited $-\left|\sigma_{z 1}\right| \leq\left|\sigma_{m}\right|$; $r \leq r_{1}$;

3) tangential to two axes $\sigma_{z 1}$ and $r$ :

$$
\begin{aligned}
& \frac{d \sigma_{z 1}(0)}{d r}=-\infty \text {; with } \mathrm{r}=0, \frac{d r\left(\sigma_{1}\right)}{d \sigma_{z 1}}=0 ; \\
& \text { with } r_{1}=r_{\max }, \frac{d \sigma_{z 1}\left(r_{1}\right)}{d r}=0 ; \\
& \text { 4) concaved } \frac{d \sigma_{z 1}\left(r_{1}\right)}{d r_{1}} \leq 0 ; \\
& \qquad \frac{d^{2} \sigma_{z 1}\left(r_{1}\right)}{d r_{1}{ }^{2}} \leq 0 .
\end{aligned}
$$

The type of function considered to variations ellipse, which meets all defined relations: it's canonic form $-\frac{x^{2}}{a^{2}}+\frac{y^{2}}{b^{2}}=1$;

matched to scheme ( Fig. 2.3 ) form -

$$
\frac{\left(\sigma_{1}-\sigma_{z 1}\right)^{2}}{c}+\frac{\left(r_{1}-r\right)^{2}}{f}=1
$$

From (2.12):

$$
\begin{gathered}
\left(\sigma_{1}-\sigma_{z 1}\right)^{2}=\frac{c f}{f}-\frac{c}{f}\left(r_{1}-r\right)^{2}= \\
=\frac{c}{f}\left[f-\left(r_{1}-r\right)^{2}\right]
\end{gathered}
$$

In (2.13) we have four parameters to be defined: $\mathrm{c}, \mathrm{f}, \sigma_{1}, \mathrm{r}_{1}$. Four relations to define them are as follows:

1) at $r=0, \sigma_{z 1}=\sigma_{1}$;

2) at $\sigma_{z 1}=0, r=r_{1}$;

$3)$ at all feasible parameters variations summative reaction in $z$ direction is equal to summative friction force acting in a section:

$$
\int_{0}^{r_{1}} \sigma_{z 1}(r) d r=N_{z} \text {, at z }=0, N_{z}=N_{z 0} ;
$$

4) at all $r_{1}$ parameter variations summative strain energy should be minimal [7]. From (2.6) strain energy defined as:

$$
\begin{gathered}
W(r)=\int_{0}^{r_{1}} \frac{\sigma_{z 1} \varepsilon_{z 1}}{2} d r= \\
=\frac{\left(1-\mu-2 \mu^{2}\right)}{E} \int_{0}^{r_{1}}\left[\sigma_{z 1}(r)\right]^{2} d r \\
\frac{d W(r)}{d r_{1}}=0 .
\end{gathered}
$$

So: 1) substitution (2.14) to (2.13) gives -

$$
f=\left(r_{1}-r\right)^{2}=r_{1}^{2}, r_{1}=\sqrt{f} ;
$$

2) substitution (2.15) to (2.13) gives -

$$
\left(\sigma_{1}-\sigma_{z 1}\right)^{2}=c ; \sigma_{1}=\sqrt{c} ;
$$

3) replacement of $\mathrm{c}$ and $\mathrm{f}$ in equation (2.13) with their values in $\mathrm{r}_{1}$ and $\sigma_{1}$ terms gives:

$$
\left(\sigma_{1}-\sigma_{z 1}\right)^{2}=\sigma_{1}^{2}-\frac{\sigma_{1}^{2}}{r_{1}^{2}}\left(r_{1}-r\right)^{2},
$$




$$
\begin{gathered}
\sigma_{1}-\sigma_{z 1}=\sqrt{\sigma_{1}^{2}-\frac{\sigma_{1}^{2}}{r_{1}^{2}}\left(r_{1}-r\right)^{2}} \\
\sigma_{z 1}=\sigma_{1}-\sigma_{1} \sqrt{1-\frac{\left(r_{1}-r\right)^{2}}{r_{1}^{2}}} \\
\sigma_{z 1}=\sigma_{1}\left[1-\sqrt{1-\frac{\left(r_{1}-r\right)^{2}}{r_{1}^{2}}}\right] .
\end{gathered}
$$

Two parameters $\sigma_{1}$ and $r_{1}$ feasible variations still remain.

From (2.16) and (2.18)

$$
\begin{gathered}
\int_{0}^{r_{1}} \sigma_{z 1}(r) d r=N_{z}(z), \\
N_{z}(z)=\sigma_{1} \int_{0}^{r_{1}} d r- \\
-\frac{1}{r_{1}} \int_{0}^{r_{1}} d r \sqrt{r_{1}^{2}-r_{1}^{2}-2 r_{1} r-r^{2}} \\
N_{z}(z)=\sigma_{1} r_{1}-\frac{\sigma_{1}}{r_{1}} \int_{0}^{r_{1}} \sqrt{2 r_{1} r-r^{2}} d r .
\end{gathered}
$$

The value $\sigma_{1} r_{1}$ in (2.19) - is the rectangle with sides $\sigma_{1}, 0$ and $0, r_{1}$ area.

It is naturally to assume that (2.19) second addendum is the fourth part of ellipse area: $1 / 4 \pi \sigma_{1} r_{1}$.

Then

$$
N_{z}(z)=\sigma_{1} r_{1}\left(1-\frac{\pi}{4}\right)
$$

From [8] integral of type: $a<0$,

$$
\begin{gathered}
\int \sqrt{a x^{2}+b x+c} d x=; \\
=\frac{2 a x+b}{4 a} \sqrt{a x^{2}+b x+c}+ \\
+\frac{b^{2}-4 a c}{8 \sqrt{-a}} \arcsin \left(\frac{2 a x+b}{\sqrt{b^{2}-4 a c}}\right)
\end{gathered}
$$

then second addendum in: $\frac{\sigma_{1}}{r_{1}} \int_{0}^{r_{1}} \sqrt{2 r_{1} r-r^{2}} d x=\frac{\sigma_{1}}{r_{1}}\left(0-\frac{r_{1}^{2}}{2} \frac{\pi}{2}\right)$, identical to (2.20).

Interdependencies

$$
\sigma_{1}=\frac{N_{z}(z)}{r_{1}\left(1-\frac{\pi}{4}\right)} r_{1}=\frac{N_{z}(z)}{\sigma_{1\left(1-\frac{\pi}{4}\right)}}
$$

allow excluding parameter $\sigma_{1}$ from (2.18):

$$
\begin{aligned}
& \sigma_{z 1}=\sigma_{1}\left[1-\sqrt{1-\frac{\left(r_{1}-r\right)^{2}}{r_{1}^{2}}}\right]= \\
& =\frac{N_{z}}{r_{1}\left(1-\frac{\pi}{4}\right)}\left[1-\frac{1}{r_{1}} \sqrt{2 r_{1} r-r^{2}}\right]
\end{aligned}
$$

From last relation -4) strain energy with (2.6) and (2.22)

$$
\begin{gathered}
W(r)=\int_{0}^{r_{1}}\left[\frac{\sigma_{z 1}}{2} \frac{\sigma_{z 1}\left(1-\mu-2 \mu^{2}\right)}{(1-\mu) E}\right] d r \\
\int_{0}^{r_{1}} \frac{N_{Z}^{2}\left(1-\mu-2 \mu^{2}\right)}{2 E(1-\mu)\left(1-\frac{\pi}{4}\right)^{2} r_{1}^{2}} \\
\left(1-\frac{1}{r_{1}} \sqrt{2 r_{1} r-r^{2}}\right)^{2} d r
\end{gathered}
$$

From (2.23) energy accurate to constant factor m:

$$
\begin{gathered}
W=m \int_{0}^{r_{1}}\left(1-\frac{1}{r_{1}} \sqrt{2 r_{1} r-r^{2}}\right)^{2} d r= \\
\frac{m}{r_{1}^{2}} \int_{0}^{r_{1}}\left(r_{1}-\sqrt{2 r_{1} r-r^{2}}\right)^{2} d r= \\
\frac{m}{r_{1}^{2}}\left[r_{1}^{2} r_{1}-2 r_{1}\left(-\frac{r_{1}^{2} \pi}{4}\right)+r_{1}^{3}-\frac{1}{3} r_{1}^{3}\right]=
\end{gathered}
$$




$$
=m r_{1}\left(2+\frac{\pi}{2}-\frac{1}{3}\right)
$$

with substitution of $m$ value:

$$
W=\frac{N_{z}{ }^{2}\left(1-\mu-2 \mu^{2}\right)}{2 E(1-\mu)\left(1-\frac{\pi}{4}\right)^{2}} \frac{\left(\frac{5}{3}-\frac{\pi}{2}\right)}{r_{1}}
$$

The energy function is inversely proportional to $r_{1}$ and minimal at $r_{1}=r_{1 \max }$. The maximal $r_{1}$ value is equal to liner's radius. Thus, the function of friction force distributed reaction (2.22) and it's maximal value at $r=0$ :

$$
\sigma_{1}\left(z_{1}\right)=\frac{N_{z}}{r_{1}\left(1-\frac{\pi}{4}\right)}
$$

2.3 Distribution of friction forces along billet axis $\left(z_{1}\right)$

Let's observe the equilibrium of differential disc in friction forces region (Fig. 2.4).

Friction force increment on the element surface, $d z_{1}$ length. eaual to the billet reaction increment $-d N_{z 1}: d N_{z 1}=k \sigma_{r} d z_{1}$.

From (2.5) $\sigma_{r}=\left(\sigma_{e}+\sigma_{1}\right) \frac{\mu}{1-\mu} ;$ and from (2.25) $\sigma_{1}=\frac{N_{z}}{r_{1}\left(1-\frac{\pi}{4}\right)}$; thus the equation for the function to be defined:

$$
\begin{aligned}
& d N_{z}=\frac{\mu}{1-\mu} k\left[\sigma_{e}+\frac{N_{z}}{r_{1}\left(1-\frac{\pi}{4}\right)}\right] d z, \\
& \frac{d N_{z}}{d z}-k \frac{\mu}{1-\mu} \frac{N_{z}}{r_{1}\left(1-\frac{\pi}{4}\right)}=k \frac{\mu}{1-\mu} \sigma_{e}
\end{aligned}
$$

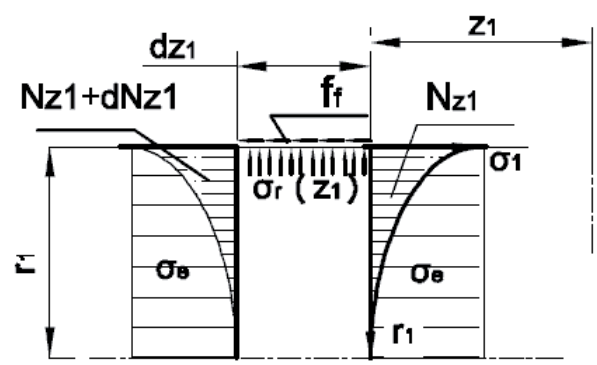

Figure 2.4 - Design scheme of friction force distribution along axis
After denoting $k_{1}=k \frac{\mu}{1-\mu},(2.26)$ will appear as:

$$
\frac{d N_{z}}{d z}-k_{1} \frac{N_{z}}{r_{1}\left(1-\frac{\pi}{4}\right)}=k_{1} \sigma_{e}
$$

The general solution of the inhomogeneous equation (2.27) by [9]:

$$
\begin{gathered}
N=e^{-\int-\frac{k_{1}}{r_{1}\left(1-\frac{\pi}{4}\right)} d z} \times \\
\times\left[\int k_{1} \sigma_{e} e^{\int-\frac{k_{1}}{r_{1}\left(1 \frac{\pi}{4}\right)} z} d z+C\right]= \\
=e^{\frac{k_{1}}{r_{1}\left(1-\frac{\pi}{4}\right)} z} \int k_{1} \sigma_{e} e^{-\frac{k_{1}}{r_{1}\left(1-\frac{\pi}{4}\right)} z} d z+
\end{gathered}
$$$$
+e^{\frac{k_{1}}{r_{1}\left(1-\frac{\pi}{4}\right)} z} C=e^{\frac{k_{1}}{r_{1}\left(1-\frac{\pi}{4}\right)} z} k_{1} \sigma_{e} \frac{e^{-\frac{\kappa_{1}}{r_{1}\left(1-\frac{\pi}{4}\right)} z}}{\frac{k_{1}}{r_{1}\left(1-\frac{\pi}{4}\right)}}+
$$$$
+e^{\frac{k_{1}}{r_{1}\left(1-\frac{\pi}{4}\right)} z} C=-\sigma_{e} r_{1}\left(1-\frac{\pi}{4}\right)+e^{\frac{k_{1}}{r_{1}\left(1-\frac{\pi}{4}\right)} z} C .
$$

From initial relation: $z_{1}=0 ; N_{z}=0$;

$$
\begin{gathered}
e^{\frac{k_{1}}{r_{1}\left(1-\frac{\pi}{4}\right)^{0}}}=1 ; C=\sigma_{e} r_{1}\left(1-\frac{\pi}{4}\right) ; \\
N_{z}=e^{\frac{k_{1}}{r_{1}\left(1-\frac{\pi}{4}\right)} z} \sigma_{e} r_{1}\left(1-\frac{\pi}{4}\right)-\sigma_{e} r_{1}\left(1-\frac{\pi}{4}\right) \\
\frac{d N_{z}}{d z}=\frac{k_{1}}{r_{1}\left(1-\frac{\pi}{4}\right)} e^{\frac{k_{1}}{r_{1}\left(1-\frac{\pi}{4}\right)} z} \sigma_{e} r_{1}\left(1-\frac{\pi}{4}\right) ;
\end{gathered}
$$

$$
\text { At } \mathrm{z}=0, \frac{d N_{z}}{d z}=k_{1} \sigma_{e}=k \frac{\mu}{1-\mu} \sigma_{e} \text { is iden- }
$$

tical to (2.27).

\subsection{Numerical estimation}

The extremal numerical estimation is possible to be made using the process real parameters. 
As example, the data from [2] and [10] was used. Alloy AK8 (analogues - AA2014, AA2214) parameters: Modulus of elasticity $E=0.74 * 10^{5} \mathrm{MPa}$; ultimate stress $-\sigma_{u}=365 \mathrm{MPa}$; Poisson's ratio $-\mu=0.33$. At the temperature level $400{ }^{\circ} \mathrm{C}: \quad E_{t}=0.4 E=0.296 * 10^{5} \mathrm{MPa}$; $\sigma_{u t} \cong 0.18 \sigma_{u}=65.7 \mathrm{MPa}$. The plastic flow stress start $\sigma_{e} \cong 3 \sigma_{u t} \cong 197.1 \mathrm{MPa}$. Liner radius $-r_{1}=3.5 "=8.9 \mathrm{~cm}=0.089 \mathrm{~m}$.

Minimal appraisal at friction factor $\mathrm{k}=0.6$

(in real process was not observed). Radial pressure on liner surface from (2.5): $\sigma_{r}=\frac{\mu}{1-\mu} \sigma_{e}=0.493 \sigma_{e}$; friction force on surface unit, on distance $z_{1}=1 \mathrm{~cm}$ :

$$
\begin{gathered}
f_{f}=N(1)=0,01 k^{\prime} \sigma_{r}=0,01 * 0.6 * \\
* 0.493 \sigma_{e}=0.296 \sigma_{e} 0.01
\end{gathered}
$$

axis stresses increment on $1 \mathrm{~cm}$ of billet length:

$\sigma_{1}(1)=\frac{N_{z}}{r_{1}\left(1-\frac{\pi}{4}\right)}=\frac{0.296 \sigma_{e} * 0.01}{0.089 * 0.215}=0.155 \sigma_{e}$

Maximal appraisal at friction factor $\mathrm{k} "=1$ : $N_{\mathrm{m}}(1)=0.493 \sigma_{\mathrm{e}}^{*} 0.01 ; \sigma_{1 \max }=0.258 \sigma_{\mathrm{e}}$.

Since the experimental data is absent, let's assume that the summative axial stresses twice as high as the beginning flow stress: $\sigma_{e}+\sigma_{1}=2 \sigma_{e}$. Then it is possible from (2.28) to define the full distance of friction forces acting:

$$
\begin{gathered}
\sigma_{e}=\frac{N_{z}}{r_{1}\left(1-\frac{\pi}{4}\right)} ; \quad N_{z}=\sigma_{e} r_{1} 0.215 ; \\
e^{\frac{k_{1}}{r_{1}\left(1-\frac{\pi}{4}\right)} z} \sigma_{e} r_{1} 0,215-\sigma_{e} r_{1} 0,215= \\
=\sigma_{e} r_{1} 0.215 ;
\end{gathered}
$$

from last: $\frac{k_{1} z}{r_{1} 0,215}=\ln 2$; with substitution $k_{1}=k^{*} 0.493$;

$$
z=\frac{0.693 * 0.215 * r_{1}}{k * 0.493}=0.302 \frac{r_{1}}{k} .
$$

At $k^{\prime}=0.6, z^{\prime}=4.48 \mathrm{~cm}$; at $k^{\prime \prime}=1, z^{\prime \prime}=2.7 \mathrm{~cm}$.
For real image obtained values:

- maximal linear stresses -

$\sigma_{z \max }=2 \sigma_{\mathrm{e}}=394.2 \mathrm{MPa}$;

- summative friction force per perimeter length unit $-N_{z}=3.77 \mathrm{MN} / \mathrm{m}$;

- billet diameter $-d=7 "=0.178 \mathrm{~m}$;

- billet maximal length $-L_{\max }=0.9 \mathrm{~m}$.

The origin point by $z_{1}$ was determined in indefinite distance from the die. Now we have to move it to the distances $z$ and $z$ " from dummy block. Summative friction forces resistance: $F_{f}=2 \pi r_{1} N_{z}=2,11 M N$.

General press force:

$$
\begin{gathered}
F_{g}=F_{e}+F_{f}=\pi r_{1}^{2} \sigma_{e}+F_{f}=4.65+2.11= \\
=6.76 M N
\end{gathered}
$$

The friction forces in this example are about $F_{f} / F_{g}=0.31-31 \%$.

As a result the friction forces act only on the small part of the billet length. Here assumed the friction force appears only on the condition of relative movement by contact surface. So, we have adjacent to dummy block short part of billet ( moving with dummy block speed) with increased peripheral stresses. Arbitrary chosen stress level $\sigma_{1}=\sigma_{\mathrm{e}}$ seems sufficient for maximal appraisal. It ensured mass transfer in stress gradient direction. Real $\sigma_{1}, \sigma_{z \max }, z$ " values should be confirmed experimentally.

Until now the press force and stresses increasing to flow beginning level, $\sigma_{e}$, was supposed with dummy block low speed. In real process $1 \ldots 3 \mathrm{~mm} / \mathrm{s}$. The stress distribution in the billet is not likely to change with such low speeds, except in two regions:

1) adjacent to dummy block region;

2) die openings region.

3. Liner and dummy block contact region

3.1 Stress state of the region

Stresses acting near adjacent surfaces of dummy block and liner (shown in Fig.3.1):

$$
\sigma_{z}=2 \sigma_{e}, \sigma_{r}=\frac{\mu}{1-\mu} \sigma_{z}
$$

$$
\text { at } \mu=0.33, \sigma_{\operatorname{rmax}}=0,493 * 2 \sigma_{e}=0.986 \sigma_{e}
$$


Third direction does not count, because of axisymmetric relations: $\varepsilon_{\theta}=0 ; u_{\theta}=0-$ strains and displacement are absent in this direction. Stresses $\sigma_{z 1}$ distributed along radius are normal to dummy block surface. They produce friction forces on the surface in radial direction, as reaction - friction stresses in the billet, in the same manner as the friction by liner surface. Maximal friction stress from (3.1):

$$
\sigma_{\text {frmax }}=k \sigma_{z \max }=k\left(\sigma_{1}+\sigma_{e}\right) \text {. }
$$

Summative friction force without surface forces accumulation effect:

$$
N_{r}=k\left(N_{z}+\sigma_{e} r_{1}\right) .
$$

Stress field geometric change by front dummy block surface is not taken into account as well.

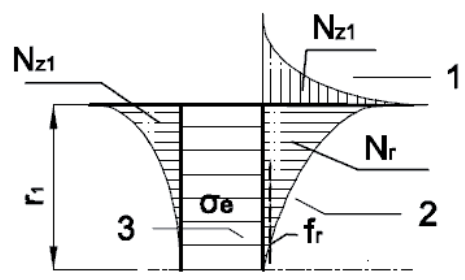

Figure 3.1 - Stress field diagram in the liner dummy block contact region: 1 - liner; 2 - billet body; 3 - dummy block front surface.

In numeric estimation from (3.2): At $k=0.6$, $\sigma_{\mathrm{fr}}^{\prime}=k^{\prime}\left(\sigma_{1}+\sigma_{e}\right)=0.6 * 2 \sigma_{e}=1.2 \sigma_{e}$; At $k^{\prime \prime}=1$, $\sigma_{\mathrm{fr}}=k^{\prime \prime}\left(\sigma_{1}+\sigma_{e}\right)=1 * 2 \sigma_{e}=2 \sigma_{e}$.

3.2 Plastic flow relations at dummy block region

So, there are two mutually perpendicular directions for the material to move in the region with the

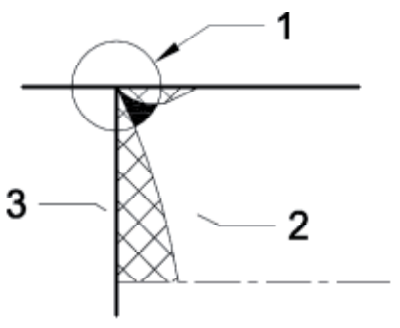

a greatest motion resistance - along dummy block and liner contact surfaces. Whereas the randomness of numerical values used above, it is rightful to state, the flow direction makes a sharp angle with both surfaces. And flow character will not change principally in all variations of the angle (Fig. 3.3 a). The indirect verification of this representation is the shape of removed from liner material in cleanout cycle. This shape resembles a pig's face and repeats constantly (Fig. 3.2) [11]:

The analogue of two cycles, extrusion beginning and cleanout, may be doubt. The main difference between those cycles is that in cleanout cycle flow occurs in free space and extrusion start flow in the compressed metal space. For the present consider the analogue as hypothesis.

As an option the plastic flow presents as shearing "strain" result. Therefore we choose a model of minimal length shearing surface (Fig.3.3 b). Than a wedge shaped dead volume in the contact "point" of the two surfaces is expected. The shear will occurred by only one surface. Here we note, the invented scheme may have a simple positive continuation - it is worth to make this shape wedge on the dummy block outer ring [12]. The wedge will work as bulldozer shovel obviously to lessen friction resistance. The region of mass transfer in this model appears as a sector with speed field per-

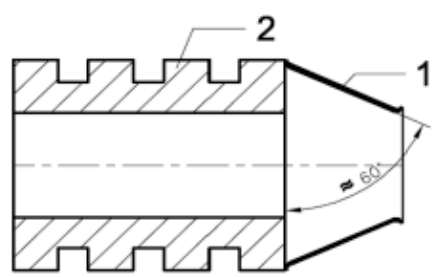

Figure 3.2 - Typical shape of removed metal - 1; cleanout tool -2

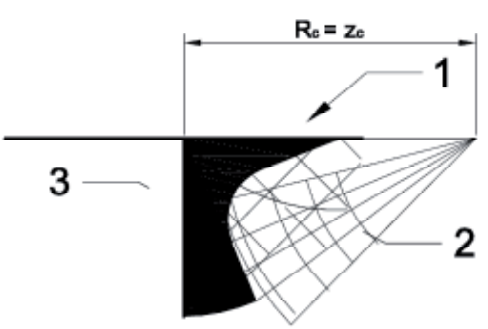

b

Figure 3.3 - Flow region at adjacent dummy block and liner surfaces - a; flow model with one shearing surface - b. 1 - liner, 2 - billet, 3 - dummy block 
pendicular to radial (of the sector) direction. The sector revolve center on the distance $R_{c}=z_{c}$, less than friction force region $-z_{\max }$. The sector angle defines the end of shearing surface - welded metal region beginning. Regarding the flow as stable and regular it is possible to consider mass transfer as sector simple revolving relative to the center till the border of shearing.

\section{Flow start. Die entrance region}

4.1 Stress state in the die entrance region

It seems reasonable to remind initial conditions to avoid uncertainty. Pressure in the billet volume and in die region rises by dummy block action till plastic flow through die opening starts. The billet equilibrium (Fig. 4.1) includes: distributed dummy block force in moving direction $-P_{z}$; distributed by die surface reaction in inverse direction $-R_{z}$; friction forces in limited region near dummy block $-F_{f}$.

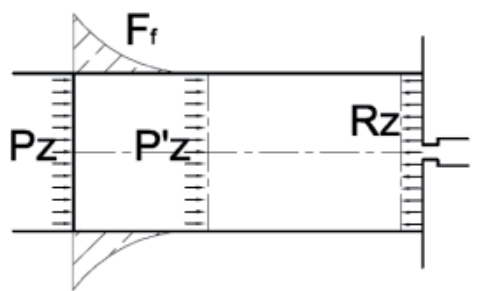

Figure 4.1 - Billet equilibrium before the plastic flow start

In accordance with scheme (fig. 4.1):

$$
P_{z}^{\prime}=P_{z}-F_{f}=R_{z} \text {. }
$$

Still we have no significant strains. Therefore the flat sections hypothesis considered rightful. That allows analysis with a static scheme. Consider round opening in the die with radius $r_{2}$. Stresses $\sigma_{\mathrm{e}}$ act by whole die surface except opening area. To explore the opening region consider a virtual cylinder with forming line as the opening edge and by now indefinite height $-h$ (Fig. 4.2).

Distributed axial pressure $\sigma_{\mathrm{e}}$ (stresses) acts on cylinder left face. Stresses on right face are absent. Radial stresses by cylindrical surface from (2.5):

$$
\sigma_{r}=\left(\frac{\mu}{1-\mu}\right) \sigma_{e}
$$

Naturally, the only way to obtain the cylinder volume equilibrium is reaction of adjacent die surface part. Additional stresses field appearance between two flat surfaces is natural as well. With geometrical relations additional stresses should act in some angle relative to the axis.

This is the signed above basic property of crystalline bodies to resist to applied loads. And always the inevitable outcome is the additional strain in stress direction. In some moment a dome shaped convex appears in the opening and limited material displacement in axis direction. The given situation relates to the first billet to be extruded. For second and the following billets with material filled die the conditions differ, mostly by increased resistance to the flow.

Let's observe an element in drawing area rz of one unit thickness for more detailed exploring (Fig. 4.3).

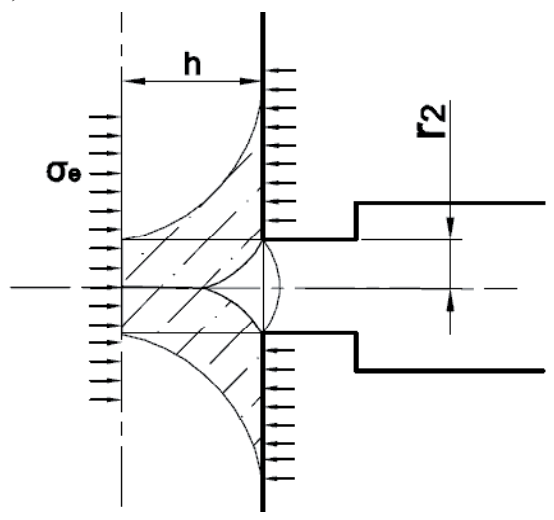

Figure 4.2 - Additional stresses field near die opening

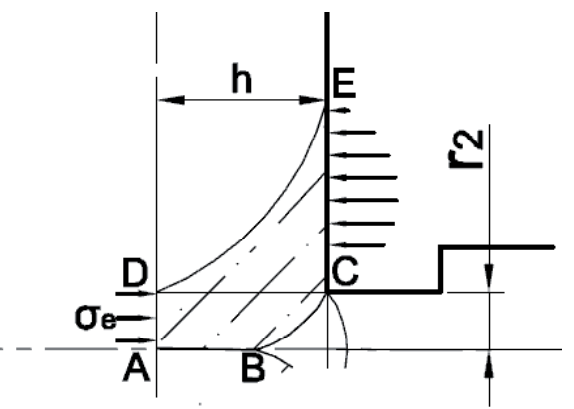

Figure 4.3 - Element scheme for additional stresses field analysis

Additional stresses field signed with lines: $\mathrm{AD}=r_{2}-$ flat surface of uniformly distributed $\sigma_{\mathrm{e}}$ stresses; $\mathrm{AB}$ - straight line collinear to the opening axis; point $\mathrm{B}$ defines the vertex of zero level additional and $z$ directed stresses field; line $\mathrm{BC}$ is the border of this field also; $\mathrm{CE}$ - strip of die reaction; 
DE - supposed outer border of additional stresses field. Axial stresses sum in each radial section of ADECB area:

$$
P=r_{2} \sigma_{\mathrm{e}}^{*} 1
$$

Here purposely geometrical relations were distort for simplification - sector with radius $r_{2}$ replaced with strip of one unit thickness. That is done in the same manner as above when friction forces by liner - billet, billet - dummy block was analyzed. Additional field configuration may be defined with the only criterion - strain energy minimum principal. As first approach let's consider a design scheme with uniformly distributed on the length L die reaction, (Fig.4.4 a). From (4.2) load per length unit:

$$
p=\frac{P}{L}=\frac{r_{2} \sigma_{e}}{L} ; \text { strain: } \varepsilon d L=\frac{p}{E} d L .
$$

Strain energy formula:

$$
W=\frac{1}{2} \frac{r_{2} \sigma_{e}}{L} \frac{r_{2} \sigma_{e}}{E L} \int_{0}^{L} d L=\frac{1}{2} \frac{P^{2}}{E L}
$$

As for die reaction, the energy dependence we have got has no minimum and inversely pro-

a

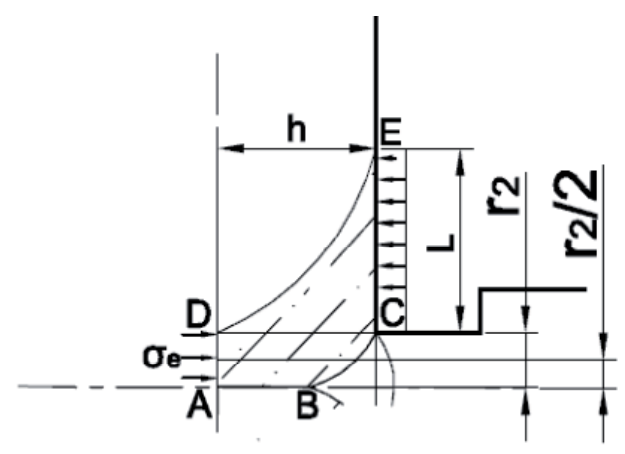

b

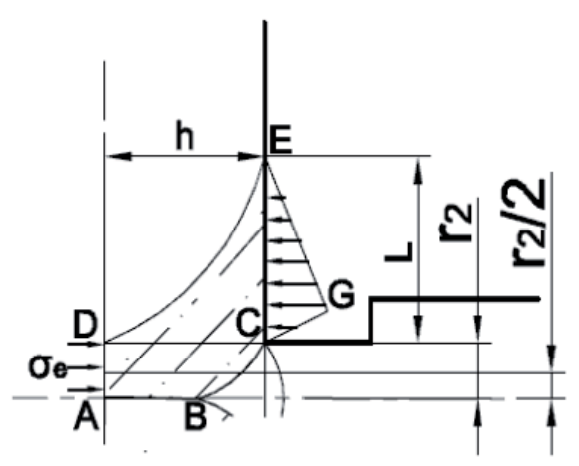

portional to L. Minimal value at maximal L $\frac{d W}{d L}=-\frac{1}{2} \frac{P^{2}}{E L^{2}}$. We note, that (4.3) formula not changes for the radial direction. As the second approach let's consider ununiformed distribution of die reaction (Fig. 4.4 b). Whereas stresses on the additional field borders are at zero level, so their maximum does exist, but do not exceed the maximum in outer region $-\sigma_{\mathrm{e}}$.

Consider $\mathrm{p}_{\max }$ in the distance not less than $\frac{r_{2}}{2}$ from opening edge and triangle shaped load distribution.

From (4.2) $\sigma_{e} r_{2}=\frac{1}{2} \sigma_{\max } L, \sigma_{\max }=\frac{2 \sigma_{e} r_{2}}{L}$; with relation $\sigma_{\max }=f\left(l=\frac{r_{2}}{2}\right)$ the variation possibility exists. Now $\sigma(l)$ current value may be defined as:

$$
\sigma,(l)=\frac{\sigma_{\max }}{\left(L-\frac{r_{2}}{2}\right)} l=\frac{2 \sigma_{e} r_{2}}{L\left(L-\frac{r_{2}}{2}\right)} l
$$

Axial strain of line segment dl:

$$
\varepsilon d l=\frac{\sigma_{\prime}(l)}{E} d l=\frac{2 \sigma_{e} r_{2}}{L\left(L-\frac{r_{2}}{2}\right) E} l d l \text {. }
$$

Strain energy, calculated separately of two strips CG and GE:

$$
\begin{gathered}
W=\int_{0}^{\left(L-\frac{r_{2}}{2}\right)} \frac{1}{2} \sigma,(l) \varepsilon= \\
\frac{1}{2}\left[\frac{2 \sigma_{e} r_{2}}{L\left(L-\frac{r_{2}}{2}\right)}\right]^{2} \frac{1}{E} \int_{0}^{\left(L-\frac{r_{2}}{2}\right)} l^{2} d l= \\
=\frac{4}{6}\left(\frac{\sigma_{e}^{2} r_{2}^{2}}{E L}-\frac{\sigma_{e}^{2} r_{2}^{3}}{2 L^{2} E}\right) \\
\sigma_{\prime \prime}(l)=\frac{2 \sigma_{e} r_{2}}{L \frac{r_{2}}{2}} l=\frac{4 \sigma_{e}}{L} l \\
W_{\prime \prime}=\frac{1}{2} \frac{\left(4 \sigma_{e}\right)^{2}}{E L^{2}} \int_{0}^{\frac{r_{2}}{2}} l^{2} d l=\frac{1}{3} \cdot \frac{\sigma_{e}^{2} r_{2}^{3}}{E L^{2}} .
\end{gathered}
$$

Figure $4.4-\mathrm{a}$ - uniformly distributed die reaction; $\mathrm{b}$ - ununiformed distribution die reaction 
Both energy parts are decreasing functions of $\mathrm{L}$, hence the function minimum is achieved on the limit defined as natural length restriction.

Except the presented two made above approaches, it is rightful to solve the problem in general terms: to define function of integral force distribution by die surface (or by random parallel to die surface, that belongs to additional stress field). Perhaps the solution already exists (or it is possible to make it) - minimum of functional: $W=\frac{1}{E} \int_{0}^{L} \sigma^{2} d l$, with relation: $\int_{0}^{L} \sigma(l) d l=$ Const; where $\sigma=f(l)$-continuous smooth function with at least one boundary point, for example $-\sigma(L=0)=0$.

Let's consider the second approach scheme with triangle reaction stress distribution for additional stress field exploration ( Fig. 4.5 ), with reaction length restriction $-L=2 r_{2}$; with maximal feasible stress value $\sigma_{\max }$ :

$$
\sigma_{\max }=\frac{2 \sigma_{e} r_{2}}{2 r_{2}}=\sigma_{e} .
$$

For simplification let's consider that resultant force applied points of distributed force $P=$ $\sigma_{e} r_{2}$ in each radial section belong to a straight line that connects the two resultant forces points on both left and die borders: $F$ and $H$. Point $F$ coordinate in radial direction $-r_{F}=r_{2} / 2$; point $H-$ $r_{H}=2 r_{2}-l^{\prime \prime \prime} ;$ from scheme fig. $4.5-$

$$
\begin{aligned}
& \frac{1}{2} l^{\prime \prime \prime} \times l^{\prime \prime \prime} \frac{\sigma_{e}}{1.5 r_{2}}=\frac{1}{2}\left(\frac{1}{2} \times \sigma_{e} 2 r_{2}\right) ; \\
& l^{\prime \prime \prime}=\sqrt{\frac{1.5 \times 2 r_{2}^{2}}{2}}=\frac{\sqrt{3}}{\sqrt{2}} r_{2}=1.22 r_{2} ; \\
& r_{H}=0.78 r_{2} r_{H}=0.78 r_{2} .
\end{aligned}
$$

From triangle $H K F$ :

$$
L^{\prime}=H K=(0.5+0.78) r_{2}=1.28 r_{2} .
$$

With all considerations only one parameter remains undefined $-h$, the distance from die surface to DA area.
Supposedly, the ratio $h / L$ ' that defines the strain energy minimum does exists. It signed as:

$$
b=\frac{h}{L^{\prime}} \text {. }
$$

Additional stress field replaced with resultant forces in each radial section. So in each point of line $\mathrm{FH}$ acts tilting force. Axial and radial components of it are follows:

$$
P_{z}=r_{2} \sigma_{e} ; \text { from (4.5) } F_{r}=P / b .
$$

Strain energy in axial direction with (4.4):

$$
W_{z} \cong \frac{1}{2} P * \frac{P}{E} h=\frac{P^{2}}{2 E} b L^{\prime}=\frac{P^{2}}{2 E} b \cdot 1.28 r_{2}
$$

Strain energy in radial direction with (4.6):

$$
W_{r} \cong \frac{1}{2} F_{r} \frac{F_{r}}{E} \cdot \frac{r_{2}+L^{\prime}}{2}=\frac{1}{2 E}\left(\frac{P}{b}\right)^{2} \cdot 0.64 r_{2}
$$

Full strain energy:

$$
\begin{gathered}
W \cong W_{z}+W_{r}= \\
=\frac{1 P^{2}}{2 E}\left(b \cdot 1.28 r_{2}+\frac{1}{b^{2}} \cdot 0.64 r_{2}\right) ;
\end{gathered}
$$

minimal energy relation:

$$
\begin{gathered}
\frac{d W}{d b}=\frac{1 P^{2}}{2 E}\left(1.28 r_{2}-3 \frac{1}{b^{3}} \cdot 0.64 r_{2}\right)=0 ; \\
b^{3}=\frac{3}{2} ; b=\sqrt[3]{\frac{3}{2}}=1,145 . \\
h=L^{\prime} b=1.28 r_{2} \cdot 1.145=1.465 r_{2} .
\end{gathered}
$$

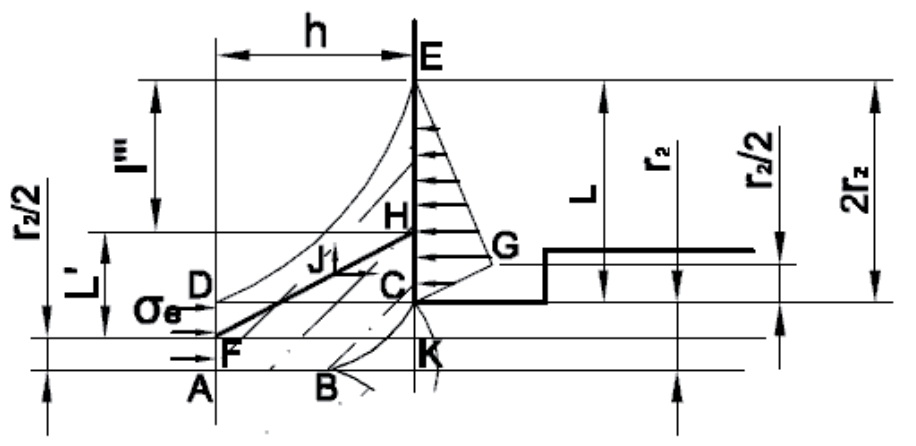

Figure 4.5 - Design scheme for second approach 
The value (4.7) we've got approximately the feasible minimal. It may be used in case of stretched die opening with parallel edges also. With additional stress field configuration defined it is possible to continue the analysis. Out of virtual cylinder the uniform axial stress field acts $\sigma_{z}=\sigma_{e}$. Two fields superposition makes the resulted field. With considered relations maximal summative axial stress should be in intersection of border DC and result-

ants line $\mathrm{FH}-$ point $\mathrm{J}: \quad \sigma_{\mathrm{zj}}=2 \sigma_{\mathrm{e}}$. Point J distance from die about: $h / 2<h^{\prime}=0.7 r_{2}$. Resultant axial stresses diagram is shown in fig. 4.6, a .

These stresses along $\mathrm{z}$ produce in radial direction stresses:

$$
\sigma_{r \max }^{\prime}=2 \sigma_{e} \frac{\mu}{1-\mu}-\sigma_{e} \frac{\mu}{1-\mu}=\frac{\mu}{1-\mu} \sigma_{e}
$$

where second addendum is radial component of additional field stresses. In transverse (again axial) direction inside cylinder, in its turn, produced by

$\sigma_{r}^{\prime}, \sigma_{z}^{\prime}$ stresses, decreasing to the opening axis,

acts: $\sigma_{z}^{\prime}=\frac{\mu}{1-\mu} \sigma_{r}^{\prime}(4.9)$

Diagram shown in fig. $4.6 \mathrm{~b}$.

From (4.9) $\sigma_{z_{\max }^{\prime}}^{\prime}=\left(\frac{\mu}{1-\mu}\right)^{2} \sigma_{e}$. Stress

level at point $\mathrm{J}$ defines, that it should coincide to plastic flow start line.

\subsection{General notes}

As shown above, in the die opening region some volume is formed with several times lower stresses relative to whole billet volume. The volume practically unloaded on the die side. Whole stresses distribution in the volume is presented in figures $4.6 \mathrm{a}$ and $\mathrm{b}$. Before next step of analysis it is necessary to verify all assumptions we've made till now, because the result we've got is too unexpected (to the author also ).

1. The superposition principal was used at the analysis start. In further calculations it was used repeatedly. 2. We supposed existence of singlevalued smooth function $\mathrm{E}$ stress and relative strain interdependence on the extrusion stresses level $\leq$ $650 \mathrm{MPa}$. 3. Existence of $\mu$-function, that defines straight to inverse strains ratio on the same stresses level was considered also. The function in present case defines principal stresses ratio in single axis stress state. 4 . The strain energy minimum principal as general relation was used. 5. Basic relations: billet material continuity and isotropy were used as mandatory restrictions.

With signed not in all proved with experiments consumptions there is always a risk to get a wrong result. Two trivial conclusions from this may be noted. In first, it is worth to make such experiments, particular for defining functions $\mathrm{E}$ and $\mu$.

In second, present analysis may in the meanwhile be considered as subject for discussion. Last note relates to following conclusions also.

\subsection{Plastic flow beginning}

Stresses field near the die opening is defined above (Figures $4.6 \mathrm{a}$ and $\mathrm{b}$ ). Maximal axial stresses near point $\mathrm{J}$ growing to some level will lead to plastic flow beginning in radial direction to opening axis. Growing axial stresses $\sigma_{z}^{\prime}$, produced by radial stresses $\sigma_{r}^{\prime}$, will act as wedge and lead to widening of plastic flow region. At some phase of the process unloaded part of volume should be pushed out of opening. The process described here we name as the "tunnel effect" by analogue to potential barrier overcoming.
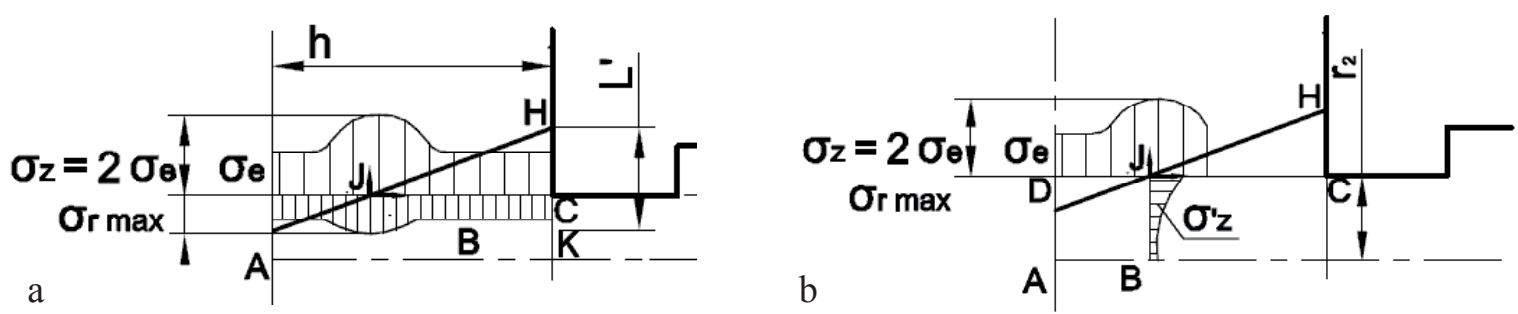

Figure 4.6 - a - Resultant stresses diagram on cylinder border; b. Axial stresses inside virtual cylinder 
4.3.1 Numerical estimation.

The example with the same relations as earlier:

Liner diameter $-D=7 "=178 \mathrm{~mm}$; profile diameter (round rod) $d=32 \mathrm{~mm} ; r_{2}=16 \mathrm{~mm}$; extrusion ratio $-n=30.9$; resultant die reaction strip length $-L^{\prime}=1.28 \mathrm{r}_{2}=20.48 \mathrm{~mm} ; b$ value from (4.5), (4.7) $b=1.145$; additional stress field height $h=1.465 r_{2}=23.4 \mathrm{~mm}$; point $\mathrm{J}$ coordinate $-h_{\mathrm{j}}=$ $0.7 r_{2}=11.2 \mathrm{~mm}$; material data: $E=0.296^{*} 10^{5} \mathrm{MPa}$; $\mu=0.33 ; \sigma_{\text {ut }}=65.7 \mathrm{MPa}$.

Let's consider that the radial stresses and axial ones proportionallv decrease to zero at onening axis: $\sigma_{r}^{\prime}(r=0)=0 ; \sigma_{z}^{\prime}(r=0)=0$.

Than from (4.9) : $\sigma_{z}^{\prime}(r)=\left(\frac{\mu}{1-\mu}\right)^{2} \sigma_{e} \cdot \frac{r}{r_{2}}$ . At this point of calculation geometrical simplifications have made above are not right if we want to avoid results distortion - real values should be defined. Section area element on feasible radius $-\mathrm{r} * \mathrm{~d} \theta$

*dr; the stress acts in the element $-\sigma_{z \max }^{\prime} r / r_{2}$. Summative force in sector $\mathrm{d} \theta$ element -

$$
\begin{gathered}
d \theta \int_{0}^{r_{2}} r d r\left(\sigma_{z \max }^{\prime} r / r_{2}\right)= \\
=d \theta\left(\frac{\mu}{1-\mu}\right)^{2} \sigma_{e} / r_{2} \frac{1}{3} r_{2}^{3} .
\end{gathered}
$$

Summative force that acts to pull out the volume (plug) of diameter $32 \mathrm{~mm}$ and height $11.2 \mathrm{~mm}$ :

$$
\begin{gathered}
P_{z}=r_{2}^{2}\left(\frac{\mu}{1-\mu}\right)^{2} \sigma_{e} \frac{1}{3} \int_{0}^{2 \pi} d \theta= \\
=2 \pi\left(\frac{\mu}{1-\mu}\right)^{2} \sigma_{e} \frac{r_{2}^{2}}{3}
\end{gathered}
$$

With known data: ultimate stress $-\sigma_{t u}$; section area $-\pi r^{2}$; the equation for $\sigma_{\mathrm{e}}$ appraisal:

$$
\begin{gathered}
\frac{2}{3} \pi\left(\frac{\mu}{1-\mu}\right)^{2} \sigma_{e} r_{2}^{2}=\pi r_{2}^{2} \sigma_{t u} ; \\
\sigma_{e}=\frac{3}{2}\left(\frac{1-\mu}{\mu}\right)^{2} \sigma_{t u}
\end{gathered}
$$

With numerical values substitution:

$$
\begin{gathered}
\sigma_{e}=4.12 \cdot \frac{3}{2} \sigma_{u}=6.18 \sigma_{u} ; \\
\sigma_{e}=6.18^{*} 65.7=406 \mathrm{MPa} .
\end{gathered}
$$

Despite the coarse appraisal, we should note, that the result is close to real.

\subsubsection{Plastic flow start. Continue}

The push out process at first stage is characterized by stresses growing and then after "pushing out", axial stresses $\sigma_{z}$ ' area increasing - smooth decreasing till full pushing plug out, and stable plastic flow forms. More detailed process description seems not right with our coarse model. Particularly, the key questions to be answered are: does the additional stresses field reproduce? Or it's configuration changes after stable flow appearance? - Answers may be achieved (on the author's opinion) in special experiments. Though, as it was made in part 2, it is possible to try to invent feasible flow model of our axisymmetric scheme. For example, scheme shown in fig. 4.7. With continuous thick curve line signed the surface of maximal in each line segment speed. Adjacent curves - surfaces of approximate proportionally decreased plastic flow speeds. (Surely, this model was built with influence of known experimental results, particularly, experiments with coordinate grids. But author can not to make straight references to other's researches, because their authors give significantly different interpretation of their results. For example as illustration in [13]).

Ensure from stability condition, speed gradient in each section perpendicular to flow, not overcome some critical value. It has the meaning - gradient value for each real condition, which not lead to continuity interruption. In traditional representa-

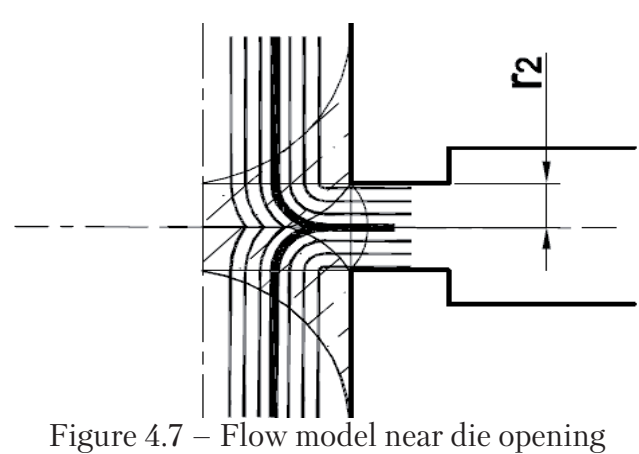


tion this means shear strain limitation. Obviously, on the author's opinion, stable flow condition may occur without shear strain at all. (Here it worth to add, one more cycle element exists in real extrusion process for first billet, which we did not consider - dummy block stops after profile exit from die. For the first quality check and profile clamp in puller jaw.)

With considerations signed above there are possible stable plastic flow criteria to formulate. Of course with other factors influence - temperature, alloy structure and process speed, which we did not consider.

5. Metal plastic flow

\subsection{General note}

As it was in part 2, devoted to liner - billet "friction", for plastic flow we have no reliably defined relations. As to the theory of plasticity criteria, they were formulated with some restricted assumptions and with such a level of abstraction that makes impossible their application to extrusion process analysis [14], [15], [16]. (The author is aware that he intrudes to theory of plasticity territory with such coarse tools as ax and sledgehammer. However, to leave this subject out of examination is unreasonable. And if not a full proof, but at least explanation of general method used for analysis has to be presented.)

\subsection{Flow relations. Basic dependencies}

Let's observe a differential cubic element of billet volume. The cube has edge $-\mathrm{dl}$ and its flats are oriented by the principal directions (Fig. 5.1).

Supposed that billet material is in the plastic state (independently to either criterion of plasticity beginning). General range of stress components are:

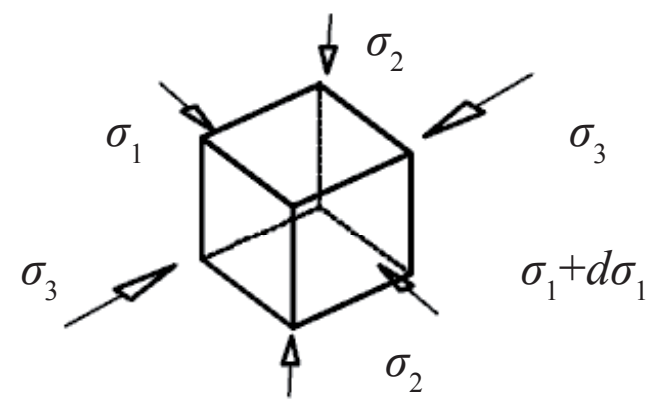

Figure 5.1 - Differential element of billet volume

$$
\begin{gathered}
0>\sigma_{1} \geq \sigma_{2}>\sigma_{3} \text { and } \\
\left|\sigma_{1}\right| \leq\left|\sigma_{2}\right|<\left|\sigma_{3}\right| .
\end{gathered}
$$

We should note, that due to above made consideration, with accuracy to volume constant re-

lation, in case: $\sigma_{1}=\sigma_{2}=\frac{\mu}{1-\mu} \sigma_{3}$, (2.5 ref), metal flow is absent (despite the deviator has significant value ). This means that plastic flow possible with the only relation: $\sigma_{1}>\sigma_{2}$ and in the increment $\mathrm{d} \sigma_{1}$ direction. Where $\mathrm{d} \sigma_{1}$ is positive and differential:

$$
\frac{d \sigma_{1}}{d l} \mathrm{dl}
$$

(5.2) has simple physical meaning - stresses gradient. One more characteristic, which cannot be forgotten: direction from $\sigma_{1}$ to $\left(\sigma_{1}+d \sigma_{1}\right)$ is collinear to mass transfer minimal energy. Theoretically possible case: $\sigma_{1}=\sigma_{2}>\frac{\mu}{1-\mu} \sigma_{3}-$ we do not consider, because it is not realized in the axisymmetric scheme. One more conclusion may be rightful-plastic flow speed is the increased function of difference $\sigma_{1}-\sigma_{2}$ and stresses gradient:

$$
\begin{gathered}
v=f\left(\sigma_{1}-\sigma_{2}\right) ; \frac{\partial v}{\partial\left(\sigma_{1}-\sigma_{2}\right)}>0 ; \\
\frac{\partial v}{\partial \sigma_{1}}>0
\end{gathered}
$$

\subsection{Uniform speed field}

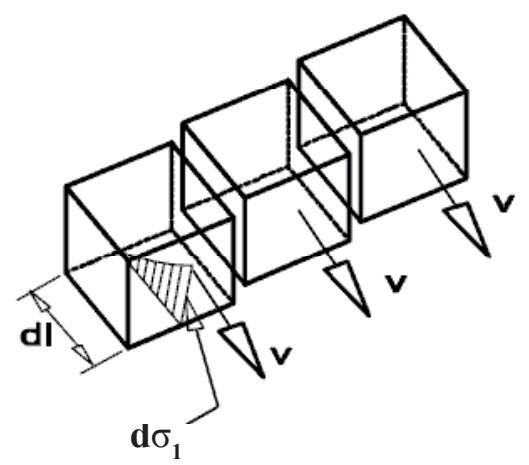

Figure 5.2 - Differential elements in uniform flow speed 
Let's consider in order of complication, firstly uniform flow speed field (Fig. 5.2).

Adjacent by side surfaces elements are under the same conditions. Stress increment $d \sigma_{1}$ distribution in dl direction accepted as proportional to length. Each element fully counterbalanced by side surfaces with adjacent ones and unbalanced by rear and front surfaces. Hence, the flow is possible only from rear to front surface with constant speed. The speed value may be represented as function:

$$
V_{y e}=K_{v}\left(T, \sigma_{e}, M\right) \cdot \frac{d \sigma_{1}}{d l},
$$

where $K_{v}$ - flow function by analogue to compliance and inversely:

$$
K_{v}=\frac{1}{E_{v}\left(T, \sigma_{e}, M\right)},
$$

where $E_{v}\left(T, \sigma_{e}, M\right)$ - function of resistance to flow by analogue to module of elasticity; $T$ - temperature, $\sigma_{\mathrm{e}}-$ flow stresses level; $M$ - constant ( or also a function) of billet material. Proportionality assumed in (5.3) $v \sim d \sigma_{1} / d l$ is only a wish. According to physical sense it may be a higher range function. This mean we have added one more assumption to all made before.

\subsection{Ununiformed speed field}

Consider plastic flow state with speed difference in one of the directions (Fig.5.3).

For example, there is a speed difference in $\sigma_{3}$ direction. And in third direction speed difference is absent as in our case of axisymmetric problem.

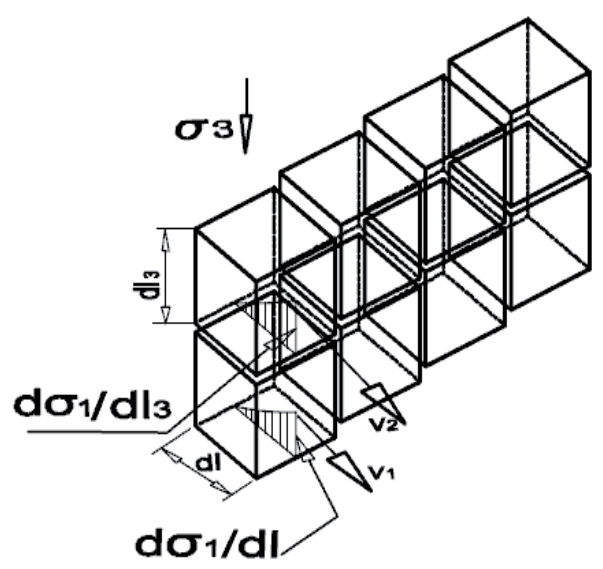

Figure 5.3 - Flow speed difference in $\sigma_{3}$ direction
I.e. in tangential direction $\sigma_{2}=\sigma_{\mathrm{Q}}$ speed difference is absent. Absolute speed difference in $\mathrm{dl}_{3}$ direction on adjacent elements:

$$
\begin{gathered}
d v\left(l_{3}\right)=v_{1}-v_{2}= \\
=\frac{1}{E_{v}}\left[\frac{d \sigma_{1}\left(l_{1}\right)}{d l}-\frac{d \sigma_{1}\left(l_{3}\right)}{d l}\right] d l ; \\
d v\left(l_{3}\right)=\frac{1}{E_{v}}\left(\frac{\partial \sigma_{1}}{\partial l_{3}}\right) d l,
\end{gathered}
$$

where $\left(\frac{\partial \sigma_{1}}{\partial l_{3}}\right)$ - stresses $\sigma_{1}$ gradient in $\sigma_{3}$ direction. Using the principal - the active stress $\sigma_{3}$ acts independently to other components, so change $\partial \sigma_{1} / \partial l_{3}$ has been compensated to equilibrium with virtual value:

$$
\frac{\partial \sigma_{3}}{\partial l_{3}}=\frac{(1-\mu)}{\mu} \cdot \frac{\partial \sigma_{1}}{\partial l_{3}} .
$$

By the assumed terms, active stress does not change. Hence, the virtual difference (5.7) compensates with flow in $1_{3}$ direction through element boarder inside it's volume. Here it is relevant to remind, we assumed continuity, isotropy and constant volume relations. So the flow difference through front element surface consists of the sum:

$$
Q_{1 F}=Q_{1 R}+Q_{3} \text {, }
$$

where $Q_{I F}$ - summative flow difference through front surfaces;

$Q_{I R}$ - flow difference through rear surfaces;

$Q_{3}$ - inversed flow inside element in $1_{3}$ direction ( Fig.5.4 ).

Mass forces will not be taken in account. Each component of flow has energy characteristic as follows:

The work spends to transfer $Q_{1 r}$ from rear to front surface $W_{1}=Q_{1}{ }^{*} d l^{*} \sigma_{1}$.

The work spends to transfer $Q_{3}$ consists of two addendums: first - flow transfer inside the element with $\sigma_{3}$ resistance and different displacement value, second - transfer to front surface with $\sigma_{1}$ resistance. The transfer works equality may be used to define two flow components ratio. We choose on the side 
element surface point $M$ with distance from rear surface $-x$, from upper surface $-y$.

The work for transferring unit of flow $q_{1}$ to point $M: w_{1}=q_{1} \sigma_{1} x$.

The work for transferring unit of flow $q_{3}$ to point $M: w_{3}=q_{3} \sigma_{3} y$.

Equality $w_{1}=w_{3}$ defines line and volume section to work equality ratio. Remaining part of displacement to front surface is the same for both flow components with the same resistance $-\sigma_{1}$. The line equation:

$$
y=\sigma_{1} / \sigma_{3}^{*} x-\text { straight line. }
$$

In considered model with accuracy to differential deviation rightful the ratio: $\frac{\sigma_{1}}{\sigma_{3}}=\frac{\mu}{1-\mu}$. From above examined example $-\mu=0.33$, $y \approx 0.493 x$.

At $\mathrm{x}=\mathrm{dl}, y \approx 0.5 d l$; than approximately:

$$
Q_{3}=0.25 Q_{1 F}
$$

According to appraisal about one fourth of the flow difference comes from $\sigma_{3}$ direction.

\subsection{Several notes regarding results}

5.5.1 (The note) As signed above we not consider the state with third direction $-\sigma_{2}$ speed difference. It would not add any sense to process physical essential understanding. Regarding to numerical estimations it would not make any sense also without values experimental verification.

5.5.2. (Essential relation) The principal stress component ratio is basic for presented plastic flow model (2.5). In ideal case, performed transforma-

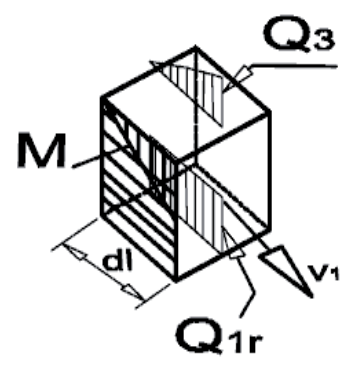

Figure 5.4 - Scheme of flows ratio in ununiformed speed field tion accurateness to ensure - the $\mu(\sigma)$ variability should be small-scale. Otherwise we get anisotropy in principal directions. That leads to large deviation of components flow ratio. Although, general flow estimation will not change significantly. The $\mu$ function should not be close to value $\mu=0.5$. This corresponds to ideal plasticity relation, and transform quality alloy to some jelly, which meet the Pascal law for liquids.

5.5.3. (Applicability) Plastic flow model is applicable with conditions: billet material continuity, continuous functions and derivatives of stresses and flow speeds; limited and continuous stresses and speed gradients. Signed conditions, on the author's opinion define the stable plastic flow.

5.5.4. (Inapplicability) The model is inapplicable in unstable plastic flow condition. The most probable cause of flow instability may be critical speed gradient value exceeding. With considered here model, this is the result of critical stress gradient exceeding $d \sigma_{1} / d l>\mathrm{Grad}$, which leads to material rupture between crystallites with opposite unconnected surfaces appearance, pressed with $\sigma_{3}$ stress, and slides relative to each other. The described above "shear strain" process often exists in practice. Undoubtedly it leads to profile structure damages and macro defects. The phenomena often cause is an unjustified speed increasing by press operator to enlarge process productivity.

Two regions of enlarged plastic flow speeds appear in extrusion process: first - contact of dummy block periphery and liner surfaces where maximal stresses act, and as signed above shear type flow is less dangerous; second - die opening region, where shear with rupture is especially harmful.

6. Press force integral graph at extrusion

Typical graph of aluminum profiles extrusion presented practically in each monograph regarding the topic. Furthermore, it may be observed in each cycle, if the press is equipped with modern control system. Hence, it presented here without references to any source, because it does not hurt copyrights of anybody ( Fig. 6.1). As illustration typical graph shape in [12], [17].

In the same manner as it done in most other sources we subdivide it to specific pieces with possible explanation of each one [5]. 
First graph piece - quick force increasing; linear part of graph - elastic billet compressing and part press metal structure (ram) elastic deformation; includes part of friction force; performed with dummy block slow-motion.

Second graph piece - nonlinear, with slowing force increasing to maximal value - plastic flow start. In accordance to present analysis results two regions of billet exist, where the plastic flow begins earlier than in the rest of the billet volume: first - dummy block and liner contact region, friction force acting region; second - die opening entrance region, additional stress field acting region, where with stresses increasing the region of "tunnel effect" plastic flow. Perhaps one more, third component of force growing to maximum exists whole billet volume conversion to plastic state, which requires additional energy to perform. According to the dislocation theory the energy spends for - redistribution, duplication and relocation of the dislocation towards crystallites surfaces [14], [18]. We still consider this component unknown. Third graph piece - force smooth decreasing till graph inflection point-dummy block slow-motion continuation - conversion to stable plastic flow.

Fourth graph piece - dummy block speed increasing by press operator to the prescribed value. Fifth graph piece - dummy block motion with constant work speed - stable extrusion process. Press force smoothly decrease practically proportionally to dummy block displacement till the work stroke end [12], stop at the butt thickness distance from die. Press force decreasing in most of publications is explained as a result of friction force de- creasing. Where friction forces are distributed by whole liner surface [15], [19]. The only word may be added, to avoid unwanted critique is that, it is not proved. The friction force in presented model very restricted, proportionally decreasing during work stroke, acts on a short distance from dummy block. Almost the whole volume of the billet, during the work stroke is not only in a plastic state but even in plastic flow state. Flow state as was shown above is performed with energy and force spending. The billet volume decreases proportionally to dummy block displacement. Hence, the force has to decrease in the same manner. The indirect verification of it may be obtained by comparison with indirect extrusion graph, where plastic flow concentrated near moveable die. Except for restricted flow volume, the process characterized by the similar components as direct extrusion: billet friction on die and liner contact surfaces, additional stresses field and "tunnel" flow near die openings. Unfortunately, author have no own experience in indirect extrusion, and does not consider himself rightful to use other authors results by the same cause as was signed above. Metal flow on the fifth graph piece is ununiformed with changing flow directions dependent on dummy block position, with uneven speed distribution by section. That is an evidence of stresses uneven distribution. There are both force components in integral scheme axial and radial directed as well. Liner to billet axial reaction always exists. It may be considered as "static frictional force".

In general, the force - stroke (pressure - ram displacement) graph should be examined as a huge

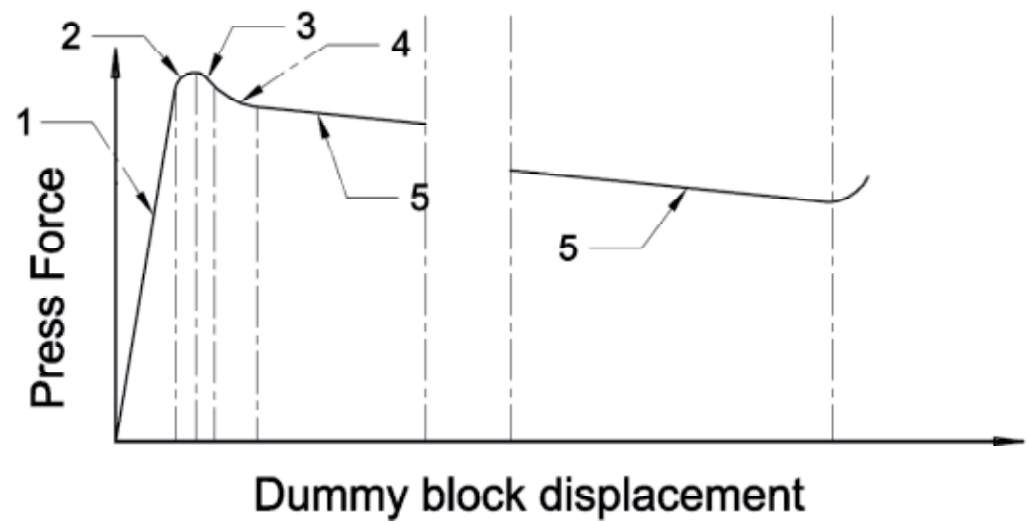

Figure 6.1 - Typical extrusion graph. By vertical - press force. By horizontal - dummy block displacement 
source of alloys parameters data. It seems as a good opportunity to obtain basic extrusion parameters without new expensive experiments setting.

7. Main analysis results

7.1 The base stress state scheme of three dimensional compressing by linear active load was developed. Principal stress component ratio in uniform stress field was defined.

7.2 Billet - liner, billet dummy block friction forces acting model was developed. The presented model does not contradicts with physical relations. The level of friction forces influence on extrusion process appraised. By appraisal, billet - liner friction force does not exceed about $31 \%$ of summative press force. The region of friction force acting was defined. The region restricted as rather short distance from dummy block, not more than the distance equal to liner radius.

7.3 Probable model of plastic flow in dummy block region is presented. It is characterized of single and minimal area shear surface.

7.4 Investigation of stress state in die opening region was fulfilled. Additional stresses field in the region revealed. Configuration of the field was defined with numerical estimation. The field in great degree defines the necessary stress level for metal flow start and stable process. The algorithm of maximal flow stress definition was developed. In real example flow stress about six times exceeds the ultimate stress level.

7.5 The flow model with restricted shear strain was presented. The model was built on example of round die opening. General "tunnel" type flow scheme was defined, bypassing axial direction. (The name "tunnel" considered in analogue of potential barrier overcoming in tunnel effect). Preferable flow direction is radial, relative to die opening.

7.6 Essential interdependencies and general relations of billet metal flow are presented.

7.7 The analyses of press load by dummy block displacement graph was fulfilled. No contradictions with the theoretically achieved results were revealed. The results experimental confirmation and further introduction to practice are proposed.

18.12.2017

Список литературы:

1. Predip, K. Saha Aluminum Extrusion Technology / K. Predip. - Ohio: ASM International, 2000 - 259 p.

2. Aluminium-guide.ru - сайт для профессионалов алюминиевой промышленности [Электронный ресурс]. - Режим доступа: $\mathrm{http} / / /$ aluminium-guide.ru/.

3. Данченко, В.Н. Производство профилей из алюминиевых сплавов / В.Н. Данченко, А.А. Миленин, А.Н.Головко; ред. В.Н. Данченко. - Днепропетровск, 2002. - 448 c.

4. Handbook of Aluminum V.1 / Edited by George E. Tollen, D. Scott Mackenzie. - Marcel Dekker. Inc., New York Basel. - CRC Press, 2003. $-1310 \mathrm{p}$.

5. Sheppard, T. Extrusion of Aluminum Alloys / T. Sheppard. - KLUWER ACADEMIC PUBLISHERS, Dortrecht, Boston, London, 1999. $-420 \mathrm{c}$

6. Flitta, I. Nature of Friction in Extrusion Process and its Effect on Material Flow / I. Flitta, T. Sheppard // Materials Science and Technology. - IoM Communications Ltd, 2003. - Volume 19. - Issue 7. - P. 837-846.

7. Вариационные принципы механики. Сборник статей классиков науки / Под ред Л.С.Полак. - Физматлит, 1959. - 930 с.

8. Смолянский, М.Л. Таблицы Неопределенных Интегралов / М.Л. Смолянский. - М.,1965. - 112 с.

9. Власов, А.К. Курс высшей математики / А.К. Власов. - Ленинград, ОГИЗ, Государственное издательство технико-теоретической литературы, 1946. - 1000 с.

10. Online Materials Information Resource [Электронный pecypc]. - Режим доступа: www.asm.matweb.com.

11. Castool Tooling Systems [Электронный ресурс]. - Режим доступа: http://www.castool.com/product/clean-out-block.

12. Today's Understanding of the Function and Benefit of Dummy Block Design [Электронный ресурс] / Paul Robbins [и др.] // ET Dummy Block Paper. - 2016. - C. 2, 4, 9. - Режим доступа: http://www.castool.com/sites/default/files/publications/ET\%20 Dummy\%20Block\%20Paper\%20-\%20May\%202016.pdf.

13. Aluminum Extrusion Council [Электронный pecypc]. - Режим доступа: www.aec.org.

14. Миркин, Л.И. Физические основы прочности и пластичности / Л.И. Миркин. - Изд. МГУ, М, 1968. - С. $184-241$.

15. Малинин, Н.Н. Прикладная теория пластичности и ползучести: учебник для студентов вузов / Н.Н. Малинин. - М., Машиностроение, 1975. $-400 \mathrm{c}$.

16. E.A. de Souza Neto Computational Methods for Plasticity: Theory and Applications / E.A. de Souza Neto, D. Peric, D.R.J. Owen. Publ. John Wiley\&Sons, 2009. - 814 c. - ISBN0470694521.

17. [Электронный ресурс]. - Режим доступа: http://www.egr.msu.edu/ pkwon/me477/bulkforming2.pdf.

18. JX Liu A strain gradient plasticity theory with application to wire torsion [Электронный pecypc] / J.X. Liu, T. ElSayed // International Journal of Damage Mechanics. - 2014. - Vol. 24. - Issue 4. - C. 512-528. - Режим доступа: https://doi. org/10.1177/1056789514537920.

19. Lilian Wang Modelling of friction for high temperature extrusion of aluminium alloys: дис. ... д-ра наук / Lilian Wang. - Delft University of Technology, 2012. - 131 c. - ISBN978-94-6182-07855. 
References:

1. Predip K. Saha Aluminum Extrusion Technology. Ohio: ASM International, 2000, 259 p.

2. Aluminium-guide.ru - sajt dlya professionalov alyuminievoj promyshlennosti [Aluminium-guide.ru - site for professionals of the aluminum industry]. Available at: http://aluminium-guide.ru/.

3. Danchenko V.N., Milenin A.A., Golovko A.N. Proizvodstvo profilej iz alyuminievyh splavov [Production of profiles from aluminum alloys] Dnepropetrovsk, 2002, $448 \mathrm{p}$.

4. George E. Tollen, D. Scott Mackenzie (Eds) Handbook of Aluminum V.1. Marcel Dekker. Inc., New York Basel, CRC Press, 2003,1310 p.

5. Sheppard T. Extrusion of Aluminum Alloys. KLUWER ACADEMIC PUBLISHERS, Dortrecht, Boston, London, 1999,420 p.

6. Flitta I., Sheppard T. Nature of Friction in Extrusion Process and its Effect on Material Flow. Materials Science and Technology, IoM Communications Ltd, 2003, volume 19, issue 7, pp. 837-846.

7. L.S. Polak (Ed) Variacionnye principy mekhaniki. Sbornik statej klassikov nauki [Variational principles of mechanics. Collection of articles of the classics of science]. Fizmatlit, 1959, 930 p.

8. Smolyanskij M.L. Tablicy Neopredelennyh Integralov [Tables of Uncertain Integrals]. M.,1965, $112 \mathrm{p.}$

9. Vlasov A.K. Kurs vysshej matematiki [Course of Higher Mathematics]. Leningrad, OGIZ, Gosudarstvennoe izdatel'stvo tekhniko-teoreticheskoj literatury, $1946,1000 \mathrm{p}$.

10. Online Materials Information Resource. Available at: www.asm.matweb.com.

11. Castool Tooling Systems. Available at: http://www.castool.com/product/clean-out-block.

12. Paul Robbins et al. Today's Understanding of the Function and Benefit of Dummy Block Design. ET Dummy Block Paper, 2016, pp. 2, 4, 9. Available at: http://www.castool.com/sites/default/files/publications/ET\%20Dummy\%20Block\%20Paper\%20-\%20 May\%202016.pdf.

13. Aluminum Extrusion Council. Available at: www.aec.org.

14. Mirkin L.I. Fizicheskie osnovy prochnosti i plastichnosti [Physical basis of strength and plasticity]. Izd. MGU, M, 1968, pp. $184-241$.

15. Malinin N.N. Prikladnaya teoriya plastichnosti i polzuchesti: uchebnik dlya studentov vuzov [Applied theory of plasticity and creep: a textbook for university students]. M., Mashinostroenie, 1975, $400 \mathrm{p}$.

16. E.A. de Souza Neto, D. Peric, D.R.J. Owen Computational Methods for Plasticity: Theory and Applications. Publ. John Wiley\&Sons, 2009, 814 p. ISBN0470694521.

17. Available at: http://www.egr.msu.edu/ pkwon/me477/bulkforming2.pdf.

18. J.X. Liu, T. ElSayed A strain gradient plasticity theory with application to wire torsion. International Journal of Damage Mechanics, 2014, vol. 24, issue 4, pp. 512-528. Available at: https://doi.org/10.1177/1056789514537920.

19. Lilian Wang Modelling of friction for high temperature extrusion of aluminium alloys. Doctor's thesis. Delft University of Technology, 2012, 131 p. ISBN978-94-6182-07855.

Information about the author:

Boris Nudelman Engineering Services Address: Nativ Hamazalot str. , 21, App. 4 Jerusalem, post code 97830, Israel.

e-mail: nudelman.boris@gmail.com

\section{Сведения об авторе:}

Нудельман Борис Лейзерович, инженер механик

Nativ Hamazalot str. , 21, App. 4 Jerusalem, post code 97830, Israel.

e-mail: nudelman.boris@gmail.com 